\title{
PET/CT scanning with 3D acquisition is feasible for quantifying myocardial blood flow when diagnosing coronary artery disease
}

\author{
Osamu Manabe ${ }^{1}$, Masanao Naya ${ }^{2 *}$ (D), Tadao Aikawa², Masahiko Obara ${ }^{2}, K^{2}$ iichi Magota ${ }^{1}$, Markus Kroenke ${ }^{1,3}$,
} Noriko Oyama-Manabe ${ }^{4}$, Kenji Hirata ${ }^{1}$, Daiki Shinyama ${ }^{5}$, Chietsugu Katoh ${ }^{6}$ and Nagara Tamaki ${ }^{1}$

\begin{abstract}
Background: The quantification of myocardial blood flow (MBF) and coronary flow reserve (CFR) are useful approaches for evaluating the functional severity of coronary artery disease (CAD). ${ }^{15} \mathrm{O}$-water positron emission tomography (PET) is considered the gold standard method for MBF quantification. However, MBF measurements in ${ }^{15} \mathrm{O}$-water PET with three-dimensional (3D) data acquisition, attenuation correction using computed tomography $(\mathrm{CT})$, and time of flight have not been investigated in detail or validated. We conducted this study to evaluate the diagnostic potential of MBF measurements using PET/CT for a comparison of a control group and patients suspected of having CAD.
\end{abstract}

Results: Twenty-four patients with known or suspected CAD and eight age-matched healthy volunteers underwent rest and pharmacological stress perfusion studies with ${ }^{15} \mathrm{O}$-water PET/CT. The whole and three regional (left anterior descending ( $L A D)$, left circumflex ( $L C X)$, and right coronary artery $(R C A)$ territory) MBF values were estimated. The CFR was computed as the ratio of the MBF during adenosine triphosphate-induced stress to the MBF at rest. The inter-observer variability was assessed by two independent observers. PET/CT using a ${ }^{15} \mathrm{O}$-water dose of $500 \mathrm{MBq}$ and 3D data acquisition showed good image quality. A strong inter-observer correlation was detected in both the whole MBF analysis and the regional analysis with high intra-class correlation coefficients $(r>0.90, p<0.001)$. Regional MBF at rest (LAD, $0.82 \pm 0.15 \mathrm{ml} / \mathrm{min} / \mathrm{g} ; \mathrm{LCX}, 0.83 \pm 0.17 \mathrm{ml} / \mathrm{min} / \mathrm{g} ; R C A, 0.71 \pm 0.20 \mathrm{ml} / \mathrm{min} / \mathrm{g} ; p=0.74)$, MBF at stress (LAD, $3.77 \pm 1.00 \mathrm{ml} / \mathrm{min} / \mathrm{g} ; \mathrm{LCX}, 3.56 \pm 1.01 \mathrm{ml} / \mathrm{min} / \mathrm{g} ; R C A, 3.27 \pm 1.04 \mathrm{ml} / \mathrm{min} / \mathrm{g} ; p=0.62)$, and CFR $(L A D, 4.64 \pm 0.90 ; L C X, 4.30 \pm 0.64 ; R C A, 4.64 \pm 0.96 ; p=0.66)$ of the healthy volunteers showed no significant difference among the three regions. The global CFR of the patients was significantly lower than that of the volunteers $(2.75 \pm 0.81$ vs. $4.54 \pm 0.66, p=0.0002$ ). The regional analysis of the patients demonstrated that the CFR tended to be lower in the stenotic region compared to the non-stenotic region ( $2.43 \pm 0.81$ vs. $2.95 \pm 0.92, p=0.052$ ).

Conclusions: ${ }^{15} \mathrm{O}$-water PET/CT with $3 \mathrm{D}$ data acquisition can be reliably used for the quantification of functional MBF and CFR in CAD patients.

Keywords: Myocardial blood flow, Coronary flow reserve, Positron emission tomography, ${ }^{15} \mathrm{O}$-water, Three-dimensional data acquisition

\footnotetext{
* Correspondence: naya@med.hokudai.ac.jp

${ }^{2}$ Department of Cardiovascular Medicine, Hokkaido University Graduate

School of Medicine, Kita-15, Nishi-7, Kita-ku, Sapporo 060-8638, Japan

Full list of author information is available at the end of the article
} 


\section{Background}

The quantifications of myocardial blood flow (MBF) and coronary flow reserve (CFR) are useful approaches for evaluating the functional severity of coronary artery disease (CAD) [1, 2]. ${ }^{15} \mathrm{O}$-water positron emission tomography (PET) is considered the gold standard method for the quantification of MBF, because it is the only method using a freely diffusible tracer with a $100 \%$ extraction fraction [3, 4]. However, MBF quantification using PET/computed tomography (CT) with threedimensional (3D) data acquisition presents technical challenges due to increased scattering. Accordingly, PET/CT MBF measurements using ${ }^{15} \mathrm{O}$-water should be validated by comparing CAD patients and an agematched healthy control group. The aim of this study was to evaluate the diagnostic potential of MBF and CFR measurements using ${ }^{15} \mathrm{O}$-water PET/CT with 3D data acquisition.

\section{Methods}

\section{Study subjects}

Twenty-four patients with CAD or suspected CAD (age $62 \pm 12$ years; 20 males, four females) and eight agematched healthy volunteers (age $58 \pm 6$ years; seven males, one female) underwent ${ }^{15} \mathrm{O}$-water PET/CT. All patients underwent coronary angiography with standard techniques; a $\geq 50 \%$ dia stenosis was considered significant. This prospective study was approved by the Ethics Committee of Hokkaido University Hospital (UMIN ID, UMIN000013003). Written informed consent was obtained from all subjects.

\section{PET imaging acquisition}

PET was performed using a Gemini TF PET/CT scanner (Philips Healthcare, Cleveland, $\mathrm{OH}$ ) with a 64-rowdetector $\mathrm{CT}$ system. The participants were instructed to fast for at least $4 \mathrm{~h}$ and to abstain from caffeinecontaining products for at least $24 \mathrm{~h}$ prior to the PET/ CT scan [5]. A prospective ECG-triggered CT for calculating the Agatston score was performed with following parameters: tube voltage, $120 \mathrm{kVp}$; effective tube current, $100 \mathrm{mAs}$; rotation time, $0.4 \mathrm{~s}$; collimation width, $40 \times 0.625 \mathrm{~mm}$; and slice thickness, $2.5 \mathrm{~mm}$. After a low-dose CT scan at free breathing for attenuation and scatter correction, $500 \mathrm{MBq}$ of ${ }^{15} \mathrm{O}$-water was slowly administered intravenously (100 s) with a simultaneous 6-min list-mode acquisition. All PET scans were executed in 3D mode.

Pharmacological stress was induced by an intravenous injection of adenosine triphosphate (ATP) $(160 \mu \mathrm{g} / \mathrm{kg} / \mathrm{min})$ at $3 \mathrm{~min}$ before the emission scanning. The subject's heart rate and blood pressure were recorded before and at 1-min intervals during the ATP infusion. Before the attenuation correction, manual registration was created in coronal,
Table 1 The subjects' backgrounds

\begin{tabular}{llll}
\hline & Volunteers $(n=8)$ & Patients $(n=24)$ & $p$ value \\
\hline Age (years) & $58 \pm 6$ & $62 \pm 12$ & 0.10 \\
Gender (male) & $7(88 \%)$ & $20(83 \%)$ & 0.78 \\
BMI $\left(\mathrm{kg} / \mathrm{m}^{2}\right)$ & $24 \pm 3$ & $25 \pm 3$ & 0.43 \\
Hypertension & $1(13 \%)$ & $8(33 \%)$ & 0.0078 \\
Diabetes mellitus & $0(0 \%)$ & $9(38 \%)$ & 0.041 \\
Dyslipidemia & $5(63 \%)$ & $8(33 \%)$ & 0.83 \\
Smoking & $0(0 \%)$ & $11(46 \%)$ & 0.018 \\
Prior PCl or CABG & $0(0 \%)$ & $9(38 \%)$ & 0.041 \\
Agatston score & $38 \pm 48$ & $911 \pm 1,000$ & 0.0024
\end{tabular}

$B M I$ body mass index, $P C l$ percutaneous coronary intervention, $C A B G$ coronary artery bypass graft

sagittal, and transaxial views. The rest and stress PET/CT images were visually aligned for proper registration, carefully ensuring that the left ventricular myocardial activity on PET did not overlap with the lung parenchyma on CT [6]. The list-mode data were subdivided into 24 serial frames $(18 \times 10$ and $6 \times 30 \mathrm{~s})$.

Attenuation-corrected radioactivity images were reconstructed using a 3D-row action maximum-likelihood algorithm (iterations, 2; relaxation parameter, 0.012). The calcium-scoring CT was reconstructed using a window centered at $75 \%$ of the RR interval and transferred to commercially available software (Intelli Space Portal ver. 5; Philips Electronics Japan, Tokyo) to calculate the Agatston score. A calcified lesion was defined as an area of at least three connected pixels with an attenuation of $>130$ Hounsfield units (HU). The Agatston score was calculated by multiplying the area of each lesion with a weighted attenuation score dependent on the maximal attenuation within the lesion (score of 1 for 130-199 HU, 2 for 200$299 \mathrm{HU}, 3$ for $300-399 \mathrm{HU}$, and 4 for $\geq 400 \mathrm{HU}$ ) [7]. The total radiation dose was estimated about $4.2 \mathrm{mSv}$ (less than $0.1 \mathrm{mSv}$ for the scout, $1.2 \mathrm{mSv}$ for the Agatston score, $0.7 \mathrm{mSv}$ for the attenuation correction $\mathrm{CT}$, and $1.1 \mathrm{mSv}$ for each ${ }^{15} \mathrm{O}$-water PET scan).

Table 2 Hemodynamic data

\begin{tabular}{lllll}
\hline & & Volunteers & Patients & $p$ value \\
\hline Rest & HR (bpm) & $59 \pm 5$ & $62 \pm 9$ & 0.24 \\
& SBP $(\mathrm{mmHg})$ & $109 \pm 11$ & $119 \pm 15$ & 0.074 \\
& DBP $(\mathrm{mmHg})$ & $63 \pm 9$ & $62 \pm 9$ & 0.86 \\
& RPP $(\mathrm{bpm} \mathrm{mmHg})$ & $6486 \pm 1,029$ & $7520 \pm 1,471$ & 0.050 \\
Stress & HR (bpm) & $79 \pm 9^{*}$ & $77 \pm 11^{*}$ & 0.63 \\
& SBP (mmHg) & $102 \pm 11$ & $106 \pm 16$ & 0.35 \\
& DBP $(\mathrm{mmHg})$ & $59 \pm 9$ & $56 \pm 12$ & 0.45 \\
& RPP $(\mathrm{bpm} \mathrm{mmHg})$ & $8069 \pm 1345^{*}$ & $8225 \pm 1968^{*}$ & 0.66 \\
\hline
\end{tabular}

$H R$ heart rate, $b p m$ beat per minute, $S B P$ systolic blood pressure, $D B P$ diastolic blood pressure, $R P P$ rate pressure product

${ }^{*} p<0.01$ compared to at rest 

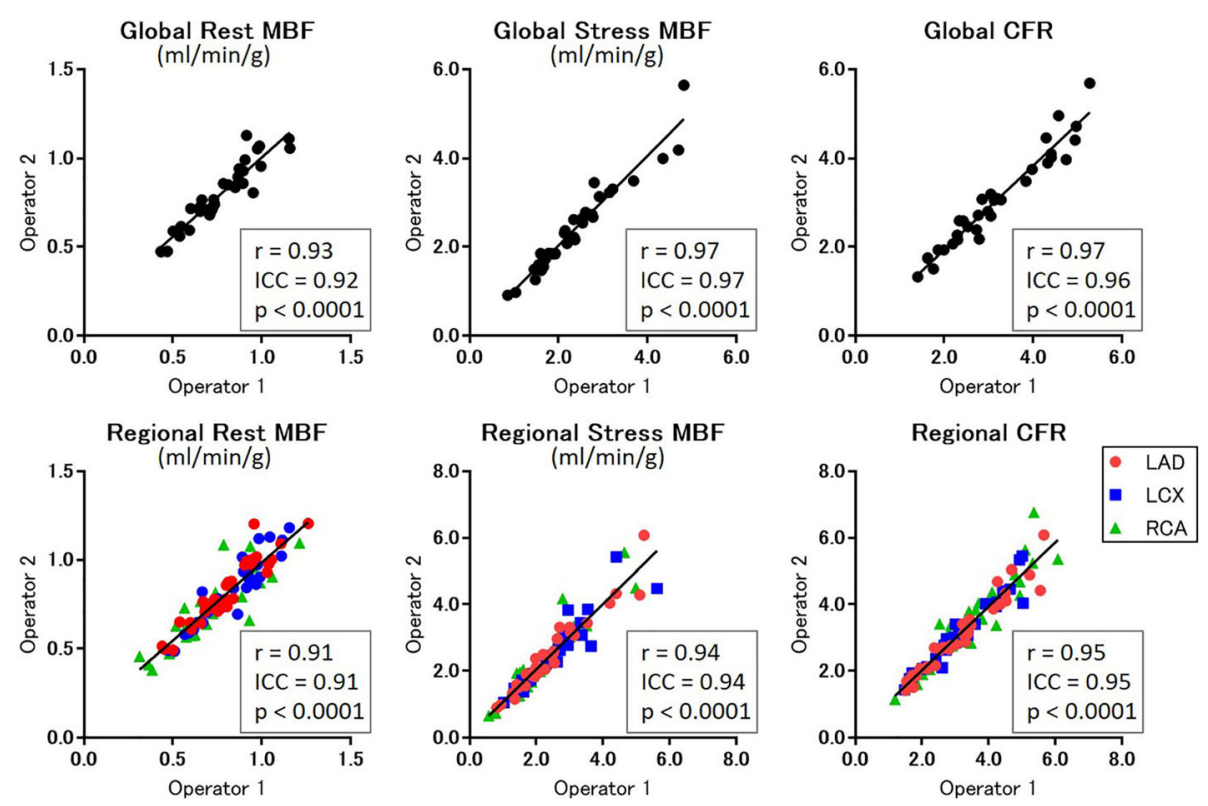

Fig. 1 Inter-observer repeatability of MBF and CFR. The results of the linear regression analysis of the variability in MBF and CFR between the two independent observers are shown. Strong inter-observer correlations were observed in both the global and regional analyses

\section{Quantification of MBF}

The MBF quantification was achieved using a software program developed in-house that semi-automatically defines regions of interest (ROI) for the left ventricular (LV) blood pool and the LV myocardium. The MBF was calculated using a one-tissue-compartment tracer kinetic model, including a myocardium-to-blood spillover correction [8]. The CFR was calculated as the ratio of the MBF during stress to the MBF at rest [9].

The MBF and CFR values were calculated from the global LV and the three coronary regions [10]. We first assessed the inter-observer variability of MBF and CFR by two independent observers (authors M.N. and T.A.). Each observer put ROIs over the whole LV myocardium and within the LV cavity to estimate the MBF and CFR using the same dynamic data. The variability of MBF and CFR compared to the healthy control group was then evaluated. We compared the MBF and CFR values from the global LV between the healthy volunteers and the patients. Finally, the regional CFR was compared among healthy volunteers and the region with and without significant stenosis in the patients who had not received prior percutaneous coronary intervention $(\mathrm{PCI})$ or coronary artery bypass grafting (CABG).

\section{Statistical analysis}

The data are expressed as mean \pm standard deviation (SD). The Wilcoxon rank-sum test was used for continuous variables. Pearson's correlation coefficient was used to evaluate the concordance between the MBF and CFR values. An analysis of variance (ANOVA) was used to compare regional CFRs among the three coronary territories. The correlation between the MBF and CFR values was assessed using linear regression analyses and intra-class correlation coefficients (ICCs). For each analysis, $p$ values $<0.05$ were considered significant. JMP ver. 12 software (SAS Institute, Cary, NC) was used for the data analyses.

\section{Results}

\section{Subjects' backgrounds}

The subjects' backgrounds are summarized in Table 1. There was no significant difference in the age, body mass index (BMI), gender, or incidence of dyslipidemia between the volunteers and patients. However, the frequencies of hypertension, diabetes, and smoking were significantly higher in the patients compared to the volunteers. Nine patients (37.5\%) had a history of PCI or CABG therapy before the PET/CT scan. The hemodynamic data included the heart rate (HR), systolic blood pressure (SBP), diastolic blood pressure (DBP), and rate pressure product (RPP). The HR and RPP in all subjects were significantly higher at stress compared to the rest scan (Table 2).

Table 3 Regional myocardial blood flow and coronary flow reserve of volunteers

\begin{tabular}{lcccc}
\hline & LAD territory & LCX territory & RCA territory & $p$ value \\
\hline $\begin{array}{l}\text { Rest MBF } \\
(\mathrm{ml} / \mathrm{min} / \mathrm{g})\end{array}$ & $0.82 \pm 0.15$ & $0.83 \pm 0.17$ & $0.71 \pm 0.20$ & 0.74 \\
$\begin{array}{l}\text { Stress MBF } \\
(\mathrm{ml} / \mathrm{min} / \mathrm{g})\end{array}$ & $3.77 \pm 1.00$ & $3.56 \pm 1.01$ & $3.27 \pm 1.04$ & 0.62 \\
CFR & $4.64 \pm 0.90$ & $4.30 \pm 0.64$ & $4.64 \pm 0.96$ & 0.66 \\
\hline
\end{tabular}

$L A D$ left anterior descending, $L C X$ left circumflex, $R C A$ right coronary artery, $M B F$ myocardial blood flow, CFR coronary flow reserve 

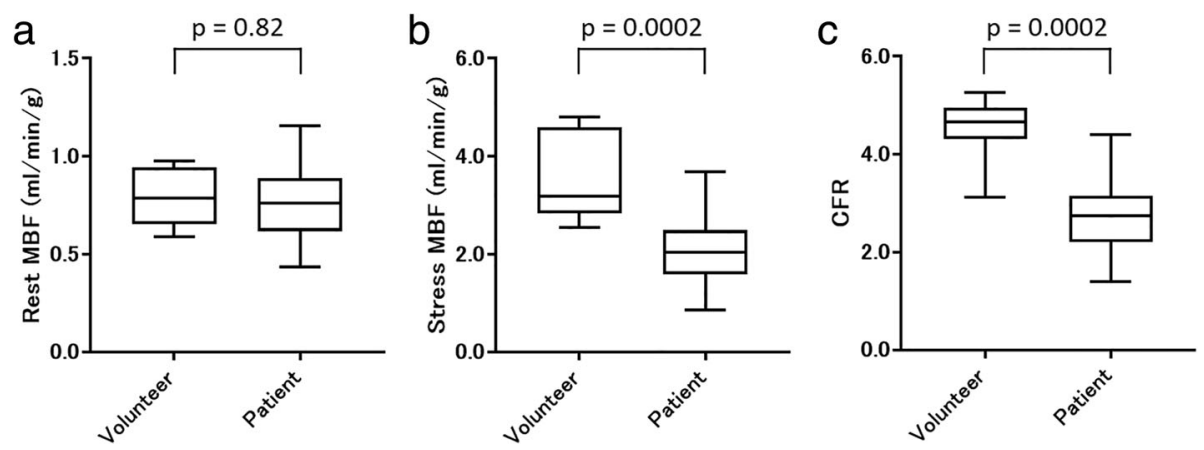

Fig. 2 Comparison of global left ventricle MBF and CFR between the volunteers and patients. Rest MBF showed no significant difference between the volunteers and patients (a). However, the stress MBF (b $2.04 \pm 0.62$ vs $3.56 \pm 0.91 \mathrm{ml} / \mathrm{min} / \mathrm{g}, p=0.0002)$ and whole CFR (c $2.75 \pm 0.81$ vs $4.54 \pm 0.66, p=0.0002$ ) of the volunteers were significantly higher than those of the patients

\section{Inter-observer correlation of MBFs and CFRs}

The variability in MBF and CFR values between the two independent observers is illustrated in Fig. 1. A strong inter-observer correlation was found for both the global analysis $(r=0.91$ for the rest MBF, $r=0.94$ for the stress $\mathrm{MBF}$, and $r=0.95$ for the CFR) and the regional analysis $(r=0.93$ for the rest MBF, $r=0.97$ for the stress MBF, and $r=0.97$ for the CFR).

\section{The variability of MBF and CFR in the control group}

The estimated regional MBF at rest, MBF at stress, and CFR of the healthy volunteers showed no significant difference among the three coronary regions (Table 3).

\section{Comparison between healthy volunteers and CAD patients}

The global CFR of the patients was significantly lower than that of the volunteers $(2.75 \pm 0.81$ vs. $4.54 \pm 0.66$, $p=0.0002$; Fig. 2). Similarly, the regional CFR of the patients was significantly lower compared to that of the volunteers $(2.63 \pm 0.88$ vs. $4.53 \pm 0.82, \quad p<0.0001)$. Among the CAD patients, the CFRs in the stenotic regions tended to be lower compared to that in the nonstenotic regions $(2.43 \pm 0.81$ vs. $2.95 \pm 0.92, p=0.052)$ (Fig. 3). The Agatston scores of the patients were significantly higher than those of the volunteers (911 \pm 1000 vs. $38 \pm 48, p=0.0024)$. A representative case of a CAD patient is shown in Fig. 4.

\section{Discussion}

We assessed the feasibility of MBF and CFR estimated by ${ }^{15} \mathrm{O}$-water PET/CT with the 3D acquisition mode. A strong inter-observer correlation of MBF and CFR in all subjects was found, and there was little variability of regional MBF and CFR obtained from the healthy control group. The regional MBF and CFR showed a highly homogenous distribution in the healthy volunteers, suggesting that the registration of $\mathrm{CT}$ and the dosage of ${ }^{15} \mathrm{O}$-water were appropriate. The CFR in the patients was significantly lower compared to the age-matched control group.

PET is the most reliable method to quantify MBF and CFR, and these quantifications can be applied to the functional severity of coronary stenosis. They can also provide prognostic information about patients with CAD and the coronary risk factors for cardiac events $[1,11]$. Supportive evidence has been reported mostly by using a stand-alone PET scanner with two-dimensional (2D) acquisition to quantify MBF and CFR $[9,12]$. Roelants et al. directly compared the MBFs between 2D and 3D acquisition modes in dogs with ${ }^{15} \mathrm{O}$-water and ${ }^{13} \mathrm{~N}$-ammonia using a stand-alone PET scanner. They concluded that quantification of MBF with $3 \mathrm{D}$ acquisition provides results

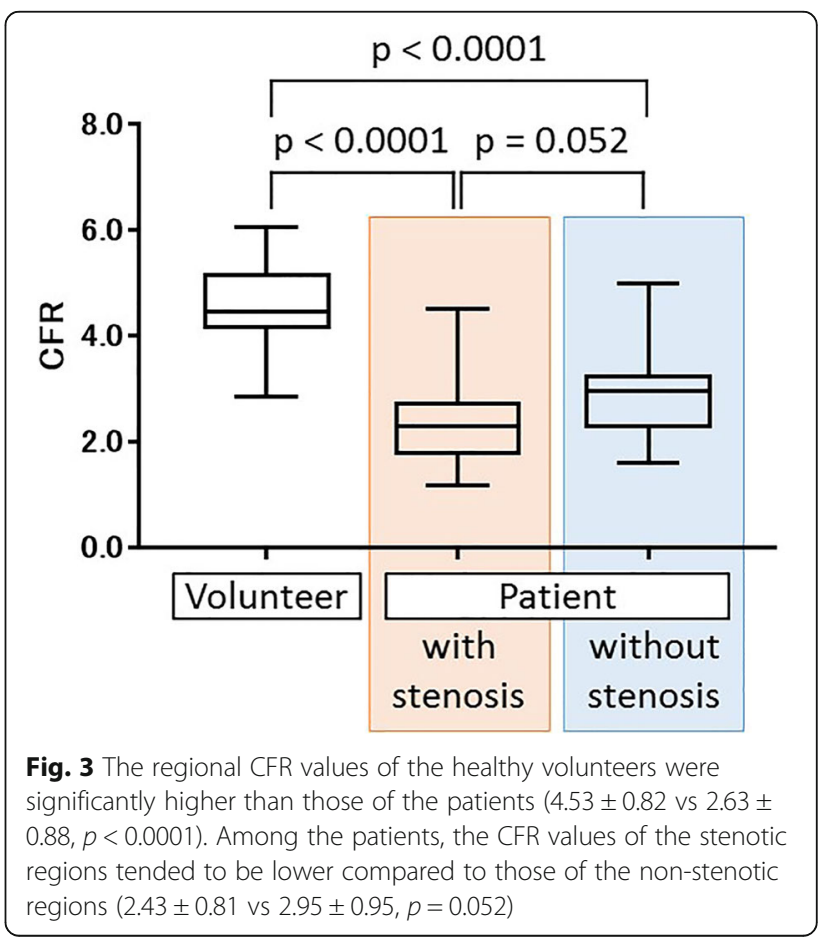




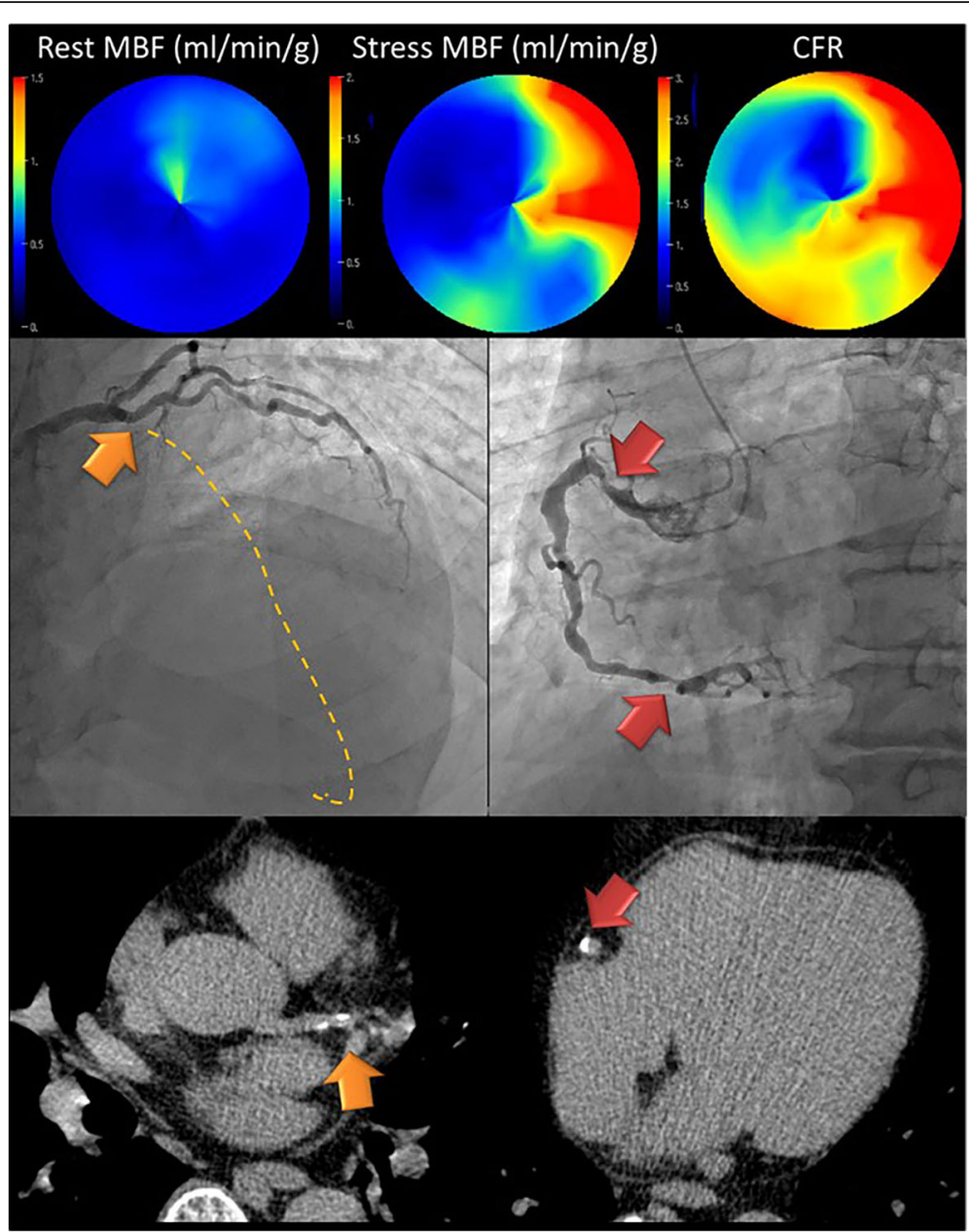

Fig. 4 Representative CAD case: A man in his 60s who had significant stenosis in the LAD (\#6 100\%; orange arrow) and RCA (\#1 70\%, \#3 90\%; red arrows). ${ }^{15} \mathrm{O}$-water PET/CT demonstrated the decrease of stress MBF and CFR in the LAD and RCA territories. The estimated whole CFR was 2.19. The CFRs in the $L A D, L C X$, and RCA territory were 1.66, 3.11, and 2.01, respectively. Calcifications were seen on the LAD and RCA (Agatston score $=97$ )

similar to those obtained with the 2D technique, despite a lower activity being injected [13]. In cases of combined PET/CT scans, a misregistration of the PET and CT due to respiratory or cardiac motion and gross physical movement of the patient causes a reduction of the MBF $[14,15]$.

${ }^{15} \mathrm{O}$-water is known as an ideal PET tracer for the quantification of MBF because of the high extraction fraction. However, ${ }^{15} \mathrm{O}$-water has a limited image quality because it is an inert, freely diffusible tracer [4]. Several automatic and manual methods have been proposed for corrections of the misalignment. Automatic methods were reported; the methods used mostly ${ }^{13} \mathrm{~N}-\mathrm{NH}_{3}$ with high uptake in the myocardium [16-18]. Rajaram et al. reported that the optimal registration of PET and CT was a useful method to avoid this artifact in ${ }^{82} \mathrm{Rb}$ PET/CT [6]. As our present findings showed high homogeneity of the regional MBF in the control group, our manual registration method is suitable for ${ }^{15} \mathrm{O}$-water PET/CT.
Tsukamoto et al. reported the values of MBF and CFR obtained from 2D data acquisition using ${ }^{15} \mathrm{O}$-water PET in patients with backgrounds similar to the present study's patients [19]. In their control group, the estimated MBF at rest, $\mathrm{MBF}$ at stress, and CFR were $0.91 \pm 0.16 \mathrm{ml} / \mathrm{min} / \mathrm{g}$, $3.66 \pm 0.81 \mathrm{ml} / \mathrm{min} / \mathrm{g}$, and $4.06 \pm 0.81$, respectively. In the stenotic regions of their CAD group, the estimated MBF at rest, MBF at stress, and CFR were $0.96 \pm 0.22$ $(\mathrm{ml} / \mathrm{min} / \mathrm{g}), 2.19 \pm 0.96(\mathrm{ml} / \mathrm{min} / \mathrm{g})$, and $2.35 \pm 0.89$, respectively. Those data are equivalent to our results from 3D data acquisition.

The quantification of MBF and CFR using PET provides additional diagnostic value for the detection of CAD and can reliably exclude multivessel CAD with very high relative predictive values [20-22]. Our present findings showed that the CFR in stenotic region tended to be lower compared to the non-stenotic region, which is similar to previous reports. The Agatston score and myocardial perfusion imaging are independent predictors. A hybrid 
PET/CT scanner allows both the integrated assessment of the physiological capacity of blood flow with the CFR and the quantification of the atherosclerotic burden with the Agatston score, which may improve the risk assessment of CAD [23, 24].

A CFR value gives the information of microvascular dysfunction in addition to flow-limiting coronary artery stenosis $[1,11]$. Several coronary risk factors such as obesity, diabetes, dyslipidemia, hypertension, renal dysfunction, and smoking are known to adversely affect microvascular function [25-27]. In the present study, the CFR values of the age-matched healthy volunteers were 1.7 times higher than those of the patients even without significant stenosis, which is thought to be related to the high frequencies of hypertension, diabetes mellitus, and smoking history in CAD patients.

This study has some methodological limitations. The sample size was relatively small. However, smaller sample sizes used in previous physiological studies were found to have sufficient power to confirm new methods. The healthy volunteers were not examined via invasive CAG. We also cannot compare 2D and 3D acquisition data because the current PET/CT scanner can obtain data only via $3 \mathrm{D}$ acquisition.

\section{Conclusions}

${ }^{15} \mathrm{O}$-water PET/CT with $3 \mathrm{D}$ data acquisition can be used reliably for the quantification of functional MBF and CFR in CAD patients.

\section{Abbreviations}

2D: Two-dimensional; 3D: Three-dimensional; ATP: Adenosine triphosphate; BMI: Body mass index; CABG: Coronary artery bypass grafting; CAD: Coronary artery disease; CFR: Coronary flow reserve; CT: Computed tomography (CT); DBP: Diastolic blood pressure; HR: Heart rate; HU: Hounsfield unit; ICC: Intra-class correlation coefficient; LV: Left ventricular; MBF: Myocardial blood flow; PCl: Percutaneous coronary intervention; PET: Positron emission tomography; ROI: Regions of interest; RPP: Rate pressure product; SBP: Systolic blood pressure

\section{Acknowledgements}

We thank Shigeo Oomagari, MSc, for his technical expertise, and Eriko Suzuki for her administrative support of this study. This study was supported in part by a grant from the Japan Society for the Promotion of Science (JSPS) KAKENHI (\#16 K10264) and bythe Takeda Science Foundation (M.N.). Only non-Philips employees had control of the data and information that might present a conflict of interest for the authors who are Philips employees.

\section{Authors' contributions}

All authors participated in the study planning, data analysis, and drafting of the manuscript and approved the final version.

\section{Competing interests}

The authors declare that they have no competing interests.

\section{Consent for publication}

Not applicable.

\section{Publisher's Note}

Springer Nature remains neutral with regard to jurisdictional claims in published maps and institutional affiliations.

\section{Author details}

'Department of Nuclear Medicine, Hokkaido University Graduate School of Medicine, Sapporo, Japan. ${ }^{2}$ Department of Cardiovascular Medicine, Hokkaido University Graduate School of Medicine, Kita-15, Nishi-7, Kita-ku, Sapporo 060-8638, Japan. ${ }^{3}$ Department of Nuclear Medicine, Klinikum rechts der Isar, Technical University of Munich, Munich, Germany. ${ }^{4}$ Department of Diagnostic and Interventional Radiology, Hokkaido University Hospital, Sapporo, Japan. ${ }^{5}$ Philips Electronics Japan, Tokyo, Japan. ${ }^{6}$ Faculty of Health Sciences, Hokkaido University Graduate School of Medicine, Sapporo, Japan.

Received: 30 March 2017 Accepted: 18 May 2017

Published online: 05 June 2017

\section{References}

1. Naya M, Di Carli MF. Myocardial perfusion PET/CT to evaluate known and suspected coronary artery disease. Q J Nucl Med Mol Imaging. 2010;54(2):145-56.

2. Knuuti J, Kajander S, Maki M, Ukkonen H. Quantification of myocardial blood flow will reform the detection of CAD. J Nucl Cardiol. 2009;16(4):497-506. doi:10.1007/s12350-009-9101-1.

3. Kaufmann PA, Gnecchi-Ruscone T, Yap JT, Rimoldi O, Camici PG. Assessment of the reproducibility of baseline and hyperemic myocardial blood flow measurements with 150-labeled water and PET. J Nucl Med. 1999:40(11):1848-56.

4. Camici PG, Crea F. Coronary microvascular dysfunction. N Engl J Med. 2007; 356(8):830-40. doi:10.1056/NEJMra061889.

5. Tomiyama Y, Manabe O, Oyama-Manabe N, Naya M, Sugimori H, Hirata K, et al. Quantification of myocardial blood flow with dynamic perfusion 3.0 Tesla MRI: validation with (15) O-water PET. J Magn Reson Imaging. 2015;42(3): 754-62. doi:10.1002/jmri.24834.

6. Rajaram M, Tahari AK, Lee AH, Lodge MA, Tsui B, Nekolla S, et al. Cardiac $\mathrm{PET} / \mathrm{CT}$ misregistration causes significant changes in estimated myocardial blood flow. J Nucl Med. 2013;54(1):50-4. doi:10.2967/jnumed.112.108183.

7. van der Bijl N, Joemai RM, Geleijns J, Bax JJ, Schuijf JD, de Roos A, et al. Assessment of Agatston coronary artery calcium score using contrastenhanced CT coronary angiography. AJR Am J Roentgenol. 2010;195(6): 1299-305. doi:10.2214/AJR.09.3734.

8. Katoh C, Yoshinaga K, Klein R, Kasai K, Tomiyama Y, Manabe O, et al. Quantification of regional myocardial blood flow estimation with threedimensional dynamic rubidium-82 PET and modified spillover correction model. J Nucl Cardiol. 2012;19(4):763-74. doi:10.1007/s12350-012-9558-1.

9. Manabe O, Yoshinaga K, Katoh C, Naya M, deKemp RA, Tamaki N. Repeatability of rest and hyperemic myocardial blood flow measurements with 82Rb dynamic PET. J Nucl Med. 2009;50(1):68-71. doi:10.2967/jnumed.108.055673.

10. Mori Y, Manabe $O$, Naya M, Tomiyama Y, Yoshinaga K, Magota K, et al. Improved spillover correction model to quantify myocardial blood flow by ${ }^{11} \mathrm{C}$-acetate PET: comparison with ${ }^{15} \mathrm{O}-\mathrm{H}_{2} \mathrm{O}$ PET. Ann Nucl Med. 2015;29(1): 15-20. doi:10.1007/s12149-014-0904-z.

11. White CW, Wright CB, Doty DB, Hiratza LF, Eastham CL, Harrison DG, et al. Does visual interpretation of the coronary arteriogram predict the physiologic importance of a coronary stenosis? N Engl J Med. 1984;310(13): 819-24. doi:10.1056/NEJM198403293101304

12. El Fakhri G, Kardan A, Sitek A, Dorbala S, Abi-Hatem N, Lahoud Y, et al, Reproducibility and accuracy of quantitative myocardial blood flow assessment with (82)Rb PET: comparison with (13)N-ammonia PET. J Nucl Med. 2009;50(7):1062-71. doi:10.2967/jnumed.104.007831

13. Roelants V, Bol A, Bernard X, Coppens A, Melin J, Gerber B, et al. Direct comparison between 2-dimensional and 3-dimensional PET acquisition modes for myocardial blood flow absolute quantification with 0-15 water and N-13 ammonia. J Nucl Cardiol. 2006;13(2):220-4. doi:10.1016/j. nuclcard.2006.01.006.

14. Gould KL, Pan T, Loghin C, Johnson NP, Guha A, Sdringola S. Frequent diagnostic errors in cardiac PET/CT due to misregistration of $C T$ attenuation and emission PET images: a definitive analysis of causes, consequences, and corrections. J Nucl Med. 2007;48(7):1112-21. doi:10.2967/jnumed.107.039792.

15. Lautamaki R, Brown TL, Merrill J, Bengel FM. CT-based attenuation correction in (82)Rb-myocardial perfusion PET-CT: incidence of misalignment and effect on regional tracer distribution. Eur J Nucl Med Mol Imaging. 2008;35(2):305-10. doi:10.1007/s00259-007-0607-y. 
16. Martinez-Moller A, Souvatzoglou M, Navab N, Schwaiger M, Nekolla SG. Artifacts from misaligned CT in cardiac perfusion PET/CT studies: frequency, effects, and potential solutions. J Nucl Med. 2007:48(2):188-93.

17. Marinelli M, Positano V, Tucci F, Neglia D, Landini L. Automatic PET-CT image registration method based on mutual information and genetic algorithms. Sci World J. 2012;2012:567067. doi:10.1100/2012/567067.

18. Alessio AM, Kinahan PE, Champley KM, Caldwell JH. Attenuation-emission alignment in cardiac PET/CT based on consistency conditions. Med Phys. 2010;37(3):1191-200. doi:10.1118/1.3315368.

19. Tsukamoto T, Morita K, Naya M, Katoh C, Inubushi M, Kuge Y, et al. Myocardial flow reserve is influenced by both coronary artery stenosis severity and coronary risk factors in patients with suspected coronary artery disease. Eur J Nucl Med Mol Imaging. 2006;33(10):1150-6. doi:10.1007/s00259-006-0082-x

20. Naya M, Murthy VL, Taqueti VR, Foster CR, Klein J, Garber M, et al. Preserved coronary flow reserve effectively excludes high-risk coronary artery disease on angiography. J Nucl Med. 2014;55(2):248-55. doi:10.2967/jnumed.113.121442.

21. Fiechter M, Ghadri JR, Gebhard C, Fuchs TA, Pazhenkottil AP, Nkoulou RN, et al. Diagnostic value of ${ }^{13} \mathrm{~N}$-ammonia myocardial perfusion PET: added value of myocardial flow reserve. J Nucl Med. 2012;53(8):1230-4. doi:10.2967/jnumed.111.101840.

22. Ziadi MC, Dekemp RA, Williams K, Guo A, Renaud JM, Chow BJ, et al. Does quantification of myocardial flow reserve using rubidium-82 positron emission tomography facilitate detection of multivessel coronary artery disease? J Nucl Cardiol. 2012;19(4):670-80. doi:10.1007/s12350-011-9506-5.

23. Schenker MP, Dorbala S, Hong EC, Rybicki FJ, Hachamovitch R, Kwong RY, et al. Interrelation of coronary calcification, myocardial ischemia, and outcomes in patients with intermediate likelihood of coronary artery disease: a combined positron emission tomography/computed tomography study. Circulation. 2008;117(13):1693-700. doi:10.1161/CIRCULATIONAHA.107.717512.

24. Chang SM, Nabi F, Xu J, Peterson LE, Achari A, Pratt CM, et al. The coronary artery calcium score and stress myocardial perfusion imaging provide independent and complementary prediction of cardiac risk. J Am Coll Cardiol. 2009:54(20):1872-82. doi:10.1016/j.jacc.2009.05.071.

25. Schindler TH, Cardenas J, Prior JO, Facta AD, Kreissl MC, Zhang XL, et al. Relationship between increasing body weight, insulin resistance, inflammation, adipocytokine leptin, and coronary circulatory function. J Am Coll Cardiol. 2006:47(6):1188-95. doi:10.1016/j.jacc.2005.10.062

26. Prior JO, Quinones MJ, Hernandez-Pampaloni M, Facta AD, Schindler TH, Sayre JW, et al. Coronary circulatory dysfunction in insulin resistance, impaired glucose tolerance, and type 2 diabetes mellitus. Circulation. 2005;111(18):2291-8. doi:10.1161/01.CIR.0000164232.62768.51.

27. Kaufmann PA, Gnecchi-Ruscone T, Schafers KP, Luscher TF, Camici PG. Low density lipoprotein cholesterol and coronary microvascular dysfunction in hypercholesterolemia. J Am Coll Cardiol. 2000;36(1):103-9.

\section{Submit your manuscript to a SpringerOpen ${ }^{\circ}$ journal and benefit from:}

- Convenient online submission

- Rigorous peer review

Open access: articles freely available online

- High visibility within the field

Retaining the copyright to your article

Submit your next manuscript at $>$ springeropen.com 